\title{
Co-cultivated cells integration into bacterial cellulose scaffold as a new device for tissue regeneration
}

\author{
Rossana Baggio Simeoni ${ }^{1}$, Julio Cesar Francisco ${ }^{* 1,2}$, Ricardo Cunha ${ }^{3,4}$, Marco André Cardoso ${ }^{5}$, Katherine Athayde T Carvalho ${ }^{3}$ and Luiz \\ Cesar Guarita-Souza ${ }^{1}$ \\ ${ }^{1}$ Experimental Laboratory School of Health Sciences of Pontifical Catholic University of Paraná (PUCPR), Curitiba, PR, Brazil \\ ${ }^{2}$ Department of Medicine of University of São Paulo, (USP) São Paulo, Brazil \\ ${ }^{3}$ Cell Therapy and Biotechnology in Regenerative Medicine Research Group, Pelé Pequeno Príncipe Institute, Curitiba, PR, Brazil \\ ${ }^{4}$ Department of physiology, University Positivo (UP), Curitiba, PR, Brazil \\ ${ }^{5}$ Department of Pharmacy, Federal University of Paraná (UFPR), Curitiba, PR, Brazil
}

\begin{abstract}
Regenerative medicine has now emerged as one of the most promising treatments for the patients suffering from damaged tissue. Tissue engineering has currently been based on the technology using bacterial celluloses $(\mathrm{BC})$ scaffolds as alternatives for extracellular matrix. Several types of the matrix were projected successfully to cultivate different types of cells, such as, for example, Chitosan [poly-( $\beta-1 / 4)-2$-amino-2-deoxy-D-glucopyranose], alginate, gelatin or collagen scaffolds. Nonetheless, insufficient cell proliferation into scaffolds and owing to inflammatory reaction due to scaffold biodegradation remain problems to be solved. We propose seeding cell to construct functional devices from products obtained from bacterial cellulose origin. SEM images revealed of cells attached at the BC. The BC configured an excellent device which offers enormous potential for tissue regeneration and cells cultivation.
\end{abstract}

\section{Introduction}

New devices composed of natural or synthetic materials are developing as therapeutic options specially designed to be applied in special clinical conditions, aiming to replace or regenerate damaged using tissue engineering[1]. Cellular therapy is a new clinical approach for the repair of damaged tissue. Its potential use in reconstructive surgery cardiac surgery is becoming a reality.

A number of biomaterials used as scaffolds have been developed and investigated, in vitro and in vivo, for potential use in tissue engineering. Bacterial cellulose (BC) is considered to be an important potential source of scaffolding material owing to its biocompatibility [2].

$\mathrm{BC}$ has been used in the food industry for applications such as lowcalorie desserts, salads, and fabricated food, in the paper manufacturing industry to enhance paper strength, in acoustic diaphragms for audio speakers, and in the pharmaceutical industry as a filtration membrane, wound dressing and artificial skin [3,4]

Currently, there is a great enthusiasm toward attracting desired stem cells to the surface of bacterial cellulose devices as part of tissueengineering applications especially in the field of regenerative medicine.

Medical devices are used for a variety of different applications and are intended generally to attract endothelial progenitor cells (EPCs) to the surface of the membrane. The EPCs drawn to the surface would increase the potential of endothelialization, which consequently brings about smaller thrombotic events triggered by the coarse surface of a non-autologous [5] Thus, in this article, we present the membrane of bacterial cellulose as a new device for the adhesion and proliferation of skeletal muscle and mesenchymal stem cells.

\section{Methods}

The study was approved by the Institutional Animal Ethics Committee Pontifical Catholic for usage of biological material for research purposes approved under article number 555 .

\section{Bacterial Cellulose}

The bacterial cellulose was obtained commercially from the Membracel biotechnological products, Brazil.

\section{Cell isolation, proliferation assay, and cell seeding}

Skeletal myoblasts were isolated after biopsy of the skeletal muscle of the lower limb, according to the technique of Delaporte [6]. Mesenchymal cells were isolated through bone marrow aspiration of the poster superior iliac crest of Wistar rats 14. After cell centrifugation and separation according to density using the Ficoll-Paque PLUS solution (Amersham Biosciences), the mesenchymal cells adhered to the surface of the plate, while those of hematopoietic origin did not. After centrifugation of the bone marrow cells, the mononuclear cells were distributed in flasks, and, after 48 hours, they were washed with PBS, and only the stromal cells remained adhered, containing the mesenchymal cells. The assays were performed in $25-\mathrm{cm} 2$ flasks, and

Correspondence to: Julio Cesar Francisco, Experimental Laboratory School of Health Sciences of Pontifical Catholic University of Paraná (PUCPR), Curitiba, PR, Brazil, E-mail: julio.apfr@gmail.com

Key words: regenerative medicine, Ficoll-Paque, SEM analysis, cellulose scaffold

Received: October 07, 2016; Accepted: October 29, 2016; Published: October 31,2016 
the cells were distributed in the proportion of 2 skeletal myoblasts to 1 mesenchymal cell (2:1), approximately $5 \times 105 / \mathrm{mL}$ per 14 days. The culture medium used was DMEM (Dulbecco's Modified Eagle Medium) containing 15\% Fetal Calf Serum (FCS), 1\% of antibiotics, and $10 \mathrm{ng} / \mathrm{mL}$ of insulin growth factor (IGF-I) (Gibcco BRL, Life Technologies, Inc, Rockville, MD). The cultures were maintained at $37^{\circ} \mathrm{C}$ in the incubator with $5 \%$ of $\mathrm{CO}_{2}$. As this was a co-cultivation, the mesenchymal cells and skeletal myoblasts were distributed for 14 days, and the culture medium was changed every 48 hours 12 . Phase contrast images were obtained with Axio Vert.A1 (Zeiss).

Before cell seeding, the BC scaffolds were sterilized with UV irradiation for $1 \mathrm{~h}$, washed three times in sterilized PBS, and then filled with $5 \mathrm{~mL}$ Dulbecco's modified Eagle medium for $24 \mathrm{~h}$ at $37^{\circ} \mathrm{C}$. The coculture were seeded onto the surface of the scaffold, the cellseeded scaffolds were cultured for 14 days, and the culture medium was refreshed every day. All scaffolds were then assessed using SEM.

\section{Scanning electron microscopy (SEM)}

The morphology and structure of the cells cultivated in BC were examined in a JEOL 1200EX II microscope (Jeol ltda, Akishima) operating at $80 \mathrm{kV}$. In order to perform the SEM analysis, material was fixed on top coverslip, dried, mounted on a stub for SEM, fixed in $2.5 \%$ (v/v) glutaraldehyde (Sigma-Aldrich) in PBS and post-fixed with $1 \%$ (v/v) and 0.1 M sodium cacodylate trihydrate (Sigma-Aldrich).

\section{Results}

\section{SEM Morphology}

The skeletal and mesenchymal cells cultivated on the bacterial cellulose membrane were revealed by SEM analysis.

\section{Discussion}

The development of new device presented itself as one potential strategic to regeneration after surface damage. Therefore, the healing process represents a major challenge in regenerative medicine. There are numerous treatment strategies for tissue injuries, including cell and scaffold-based methods. Nevertheless, one of the most important factors in regenerative medicine is the preparation of a scaffold.

Bacterial cellulose (BC), which is of special interest in food industry, has proven as a substitute for tissue reconstruction owing to its biocompatibility, revealing being an artificial skin ideal biomaterial or blood vessels replacement [2].

For tissue regeneration, $\mathrm{BC}$ scaffolds are used as an excellent basis to support the cells, helping proliferation and differentiation. However, an environment closest as possible of the physiological structure has not been achieved yet.

In this context, the present paper aims to develop a type of surface covered by co-culture cells with tissue engineering applications in the form of a 3D scaffold. The use of BC approach for colonization shown in SEM completely covered of cells while leaving the matrix intact, corroborated with other studies [7].

The recellularization, is beneficial to tissue regeneration that can be introduced through the activation of growth factors necessary for cell attachment, proliferation, and ultimately tissue remodeling [8].

In this study, we demonstrated the cellularization efficiency with the cultivation of mesenchymal and skeletal cells in BC provide an adequate in vitro microenvironment for adhesion and proliferation matrix scaffold.

\section{Conclusion}

Bacterial cellulose (BC) has recently attracted a great deal of attention owing to its biocompatibility, among other such as high mechanical strength, water content, crystallinity as well as an ultrafine, highly pure and should be a great promise for the near future. This study showed that the $\mathrm{BC}$ is an excellent option for Bioengineering, showing his potential for tissue regeneration with cultured cells for regenerative medicine.

\section{References}

1. Alves da Silva ML (2010) Chitosan/polyester-based scaffolds for cartilage tissue engineering: assessment of extracellular matrix formation. Acta Biomater 6: 1149-57.

2. Helenius G, Bäckdahl H, Bodin A, Nannmark U, Gatenholm P, et al. (2006) In vivo biocompatibility of bacterial cellulose. J Biomed Mater Res A 76: 431-438. [Crossref]

3. Lynd LR, Weimer PJ, van Zyl WH, Pretorius IS (2002) Microbial cellulose utilization: fundamentals and biotechnology. Microbiol Mol Biol Rev 66: 506-577, table of contents. [Crossref]

4. Petersen N, Gatenholm P (2011) Bacterial cellulose-based materials and medical devices: current state and perspectives. Appl Microbiol Biotechnol 91: 1277-86.

5. Williams DF (2008) On the mechanisms of biocompatibility. Biomaterials 29: 29412953. [Crossref]

6. Delaporte C, Fardeau (1984) The effect of serum from a patient with myeloma and diffuse muscular hypertrophy on the growth of human muscle cells in culture. $C R$ Acad Sci III 298: 49-54.

7. Wilshaw SP, Kearney JN, Fisher J, Ingham E (2006) Production of an acellular amniotic membrane matrix for use in tissue engineering. Tissue Eng 12: 2117-2129. [Crossref]

8. Luo JC, Li XQ, Yang ZM (2004) Preparation of human acellular amniotic membrane and its cytocompatibility and biocompatibility Zhongguo Xiu Fu Chong Jian Wai Ke Za Zhi 18: 108-111. [Crossref]

Copyright: (C2016 Simeoni BR. This is an open-access article distributed under the terms of the Creative Commons Attribution License, which permits unrestricted use, distribution, and reproduction in any medium, provided the original author and source are credited. 